\title{
ASSESSMENT OF JOINT FUNCTION IN ADHESIVE CAPSULITIS OF SHOULDER BEFORE AND AFTER REHABILITATION
}

\author{
Yesh Veer Singh', Santhosh Kumar Mathangi², Anirudh Chirania ${ }^{3}$, Vijay Gyanani ${ }^{4}$ \\ ${ }^{1}$ Senior Resident, Department of PMR, KGMU, Lucknow, Uttar Pradesh. \\ ${ }^{2}$ Associate Professor and HOD, Department of PMR, Christian Medical College Ludhiana, Punjab. \\ 3 Junior Consultant, APoKOS Rehabilitation Hospital, Hyderabad, Andhra Pradesh. \\ ${ }^{4}$ Senior Scientist, San Diego, CA, USA.
}

\section{ABSTRACT}

\section{BACKGROUND}

Adhesive capsulitis of shoulder is defined as a clinical syndrome. It is a common problem in day-to-day practice. It is often selflimited but can persist for years and may never be fully resolved. This condition is often referred as "Frozen Shoulder". The treatment of Adhesive capsulitis is challenging because initial treatment is painful and the mainstay of treatment is physical therapy regimen. There is no crystal-clear management protocol mentioned in available literature.

The aim of the study is to assess the efficacy of different types of conservative management protocols in adhesive capsulitis

\section{MATERIALS AND METHODS}

This study was a randomised controlled trial. 105 patients with adhesive capsulitis of shoulder were selected who fulfilled the inclusion and exclusion criteria of this study. Randomly we classified all patients into three groups. All patients recruited in Group $1 / 2 / 3$ received intra-articular Triamcinolone ( $40 \mathrm{mg}$ ) injection, Ultrasound therapy (UST) and exercises only treatment protocol respectively.

\section{RESULTS}

All groups showed significant improvement in pain, disability, SPADI score and Range of motion (ROM). Intra-articular steroid injection with exercises is the best conservative treatment protocol proved. Ultrasound therapy did not produce any significant change in outcome of patients.

\section{CONCLUSION}

Adhesive capsulitis of shoulder usually resolves spontaneously. Active, passive and assisted range-of-motion exercises are essential in the early stages of rehabilitation. When pain is still a major symptom, care must be taken to work the arm only in available range, while pain relieving modalities remain the treatment of choice. Intra-articular Triamcinolone injection acts as a best pain relieving modality.

\section{KEYWORDS}

Adhesive Capsulitis, SPADI.

HOW TO CITE THIS ARTICLE: Singh YV, Mathangi SK, Chirania A, et al. Assessment of joint function in adhesive capsulitis of shoulder before and after rehabilitation. J. Evolution Med. Dent. Sci. 2017;6(83):5783-5788, DOI: 10.14260/jemds/2017/1255

\section{BACKGROUND}

The upper extremity is a complex Neuro-Musculo-Articular entity. Good shoulder girdle function is a prerequisite for effective hand function.

It is defined as a clinical syndrome and first described by Codman as a painful restriction in shoulder range of motion in a patient with normal radiographs.(1) Adhesive capsulitis is usually an idiopathic condition but can be associated with diabetes, inflammatory arthritis, Dupuytren's disease, hyperlipidaemia, hyperthyroidism, cardiac disease and hemiplegia. ${ }^{2,3)}$ Incidence in general population is $2-5 \%$ and $10-35 \%$ in diabetics. ${ }^{(3,4)}$

'Financial or Other Competing Interest': None.

Submission 28-08-2017, Peer Review 02-10-2017,

Acceptance 09-10-2017, Published 16-10-2017.

Corresponding Author:

Dr. Mathangi Santhosh Kumar,

Associate Professor and Head,

Department of PMR,

Christian Medical College and Hospital,

Ludhiana-141008, Punjab.

E-mail: msanthosh365@yahoo.com

DOI: $10.14260 /$ jemds/2017/1255

\section{(c) (1) $(5)$}

The Shoulder pain is third most common cause of musculoskeletal disability in Workplace after Low Back pain and Neck pain.

The Adhesive capsulitis is a common yet poorly understood condition. It is a common problem in day-to-day practice. It is often self-limited but can persist for years and may never be fully resolved. $(1,5,6,7,8,9,10,11)$ This condition is often referred as "Frozen Shoulder".

The treatment of Adhesive capsulitis is challenging because initial treatment is painful. The mainstay of treatment is physical therapy regimen $(2,3,4)$ which most of the patients find difficult to follow due to pain. There is no crystal clear management protocol available in literatures because the Frozen shoulder research has been limited by the heterogeneous nature of the patient group presenting with shoulder stiffness, as represented by these various definitions.

This project is a humble attempt to assess the role of deep heat modalities and local infiltration of corticosteroid injection in Adhesive capsulitis of the Shoulder. 


\section{AIMS AND OBJECTIVES}

To assess the efficacy of different types of conservative management protocols in adhesive capsulitis.

\section{MATERIALS AND METHODS}

This study was done during the period from October 2011 to March 2013. After institutional ethics committee clearance, cases were selected from patients of both sexes and of both urban \& rural population with complaint of shoulder pain and restricted Range of motion (ROM) attending OPD of Department of Physical Medicine \& Rehabilitation, Sambhunath Pandit Hospital, Kolkata. As a convenient sample, we took 35 subjects for each group totalling to 105 for 3 groups.

\section{Inclusion Criteria}

- $\quad$ Stage 1 and 2 Adhesive capsulitis of shoulder.

- $\quad$ Patients of both sexes of age group 18 years and above.

- Patients who had given written consent to enter into the treatment procedure.

- Adequate communication ability to cope with the verbal rating score for pain and disability.

- $\quad$ ESR, Blood Sugar (F and PP), Bleeding time and clotting time (BT/CT) Within normal range.

\section{Exclusion Criteria}

- Patients who were not willing or not in a sound mental state to give consent.

- Unable to follow up steps of command.

- Referral pain from other causes.

- Patient with Diabetes mellitus (DM) \& hypertension (HTN).

- Systemic and local infection (Septic arthritis).

- Ultrasound therapy is contraindicated.

- Patient with connective tissue disorder.

- Patient with internal derangement of shoulder.

- Patient with inflammatory joint disease \& Osteoarthritis.

- $\quad$ Rotator cuff tears (partial/complete).

- Current Warfarin treatment \& bleeding diathesis.

- Patient with Serious cardiac \& neurological problem.

- Patient with Malignancy.

- $\quad$ Allergy to Local Anaesthesia (LA).

- New Fracture around Shoulder joint.

- Peripheral neuropathy.

\section{Study Period}

October 2011 - March 2013 (18 months).

\section{Sample Size}

$105(n=105)$ Subjects of Adhesive capsulitis, but only 99 patients completed study.

\section{Study Design}

Randomised controlled trial.

\section{Randomisation}

Randomisation was done after recruitment of patient in the study by computer generated random number list for allotment.

\section{Assessment}

The study was conducted over a period of approximately 1.5 years. Ethical committee clearance with the study protocol and patient examination proforma had been prepared. Patient was assessed on first visit $\left(\mathrm{V}_{1}\right)$ and after initial assessment, the patients had been recruited into three groups (Group - 1/2/3) randomly and allotted different treatment plan to each group. All patients were recruited by single doctor and also all interventions performed by single doctor according to standardised protocol. Physical examination of all patients repeated on visit 2 ( $6^{\text {th }}$ Week) and visit $3\left(12^{\text {th }}\right.$ Week) by same doctor.

\section{Parameters to be used}

\section{Clinical and Functional Parameter}

Pain Scale \& Disability Scale from SPADI, Total SPADI score, Goniometry for ROM.

\section{Investigational Parameter}

X-Ray Shoulder (AP/LT), Routine blood examination, Blood Sugar (F/PP), Bleeding \& Clotting (BT \& CT) time, USG Shoulder, ECG.

\section{Group 1}

All patients in this group treated with three Intra-articular injections (posterior approach) of $1 \mathrm{~mL}$. Triamcinolone acetonide $(40 \mathrm{mg})$ and $1 \mathrm{~mL}$ Bupivacaine $(0.5 \%)$ on a 2 -week interval and followed by conventional Exercise therapy.

\section{Group 2}

All patients in this group treated with Ultrasound therapy (Continuous mode) with $1 \mathrm{MHz}$ frequency and $1.5 \mathrm{~W} / \mathrm{cm}^{2}$ intensity locally for 15 minutes every day for 15 sessions and followed by conventional exercise therapy.

\section{Group 3}

All patients in this group treated with Conventional Exercise therapy only.

\section{Outcome Measures}

After completion of study all the available data were analysed.

Software used: Statistical Analysis was performed with the help of Epi Info (TM) 3.5.3. EPI Info is a trademark of the Centers for Disease Control and Prevention (CDC).

Descriptive statistical analysis was performed to calculate the means with corresponding standard deviations. One Way Analysis of Variance (ANOVA) followed by Tukey's Test was performed with the help of Critical Difference (CD) or Least Significant Difference (LSD) at $5 \%$ and $1 \%$ level of significance to compare the mean values. Test of proportion was used to find the Standard Normal Deviate (Z) to compare the difference in proportions and chi-square $\left(\mathrm{X}^{2}\right)$ test was performed to find the associations. The $\mathrm{p} \leq 0.05$ is considered as statistically significant.

\section{RESULTS}

This was a randomised control study. Total number of patients recruited in this study was 105 , but only 99 patients completed this study so only these 99 patients included in statistical analysis. Subjects were randomly chosen from the patients registered at Outpatient Door (OPD). 


\begin{tabular}{|c|c|c|c|}
\hline $\begin{array}{c}\text { Groups and other } \\
\text { Statistical } \\
\text { Parameters }\end{array}$ & $\begin{array}{c}\text { Pre- } \\
\text { Initiation } \\
(\mathrm{P} 1 \%)\end{array}$ & $\begin{array}{c}1^{\text {st }} \\
\text { Follow-up } \\
(\mathrm{P} 2 \%)\end{array}$ & $\begin{array}{c}2^{\text {nd }} \\
\text { Follow-up } \\
\text { (P3\%) }\end{array}$ \\
\hline Group-1 (n = 35) & $88.97 \pm 1.81$ & $41.31 \pm 2.90$ & $22.11 \pm 2.90$ \\
\hline Group-2 (n= 33) & $90.42 \pm 1.65$ & $76.66 \pm 2.35$ & $62.75 \pm 2.51$ \\
\hline Group-3 $(n=31)$ & $92.00 \pm 1.61$ & $81.80 \pm 1.85$ & $69.80 \pm 2.95$ \\
\hline ANOVA F $_{2,96}$ & 0.78 & 82.64 & 86.35 \\
\hline $\mathrm{p}$-value & $>0.0$ & $<0.01$ & $<0.01$ \\
\hline $\begin{array}{c}\text { At } 5 \% \text { level of } \\
\text { significance }\left(C_{5}\right)\end{array}$ & 15.93 & 22.89 & 26.14 \\
\hline $\begin{array}{c}\text { At } 1 \% \text { level of } \\
\text { significance }\left(\mathrm{CD}_{1}\right)\end{array}$ & 21.05 & 30.26 & 34.55 \\
\hline \multicolumn{4}{|c|}{$\begin{array}{c}\text { Table 1. SPADI Pain Score (P\%) (Mean } \pm \text { S.E.) at Different } \\
\text { Visits \& Statistical Analysis }\end{array}$} \\
\hline
\end{tabular}

There were no significant differences in P1\% of the three groups $\left(F_{2,96}=0.78 ; p>0.05\right)$. As per the $C D$, there were no significant differences in the mean $\mathrm{P} 1 \%$ values of the three groups ( $\mathrm{p}>0.05)$.

There were significant differences of $\mathrm{P} 2 \%$ of the three groups $\left(\mathrm{F}_{2,96}=82.64 ; \mathrm{p}<0.01\right)$. As per the $\mathrm{CD}$, the mean $\mathrm{P} 2 \%$ was significantly lowest in Group-1 as compared to Group-2 and Group-3 ( $\mathrm{p}<0.05)$. But there was no significant difference in mean P2\% of Group-2 and Group-3 ( $>>0.05$ ).

There were significant differences of $\mathrm{P} \%$ of the three groups $\left(F_{2}, 96=86.35 ; p<0.01\right)$. As per the $C D$, the values of mean P3\% was significantly lowest in Group-1 compared to that of Group-2 and Group-3 $(\mathrm{p}<0.05)$. But there was no significant difference in mean P3\% for Group-2 and Group-3 ( $>00.05)$.

ANOVA showed that there was significant reduction in mean values of pain scale $(\%)$ in subsequent follow-ups $\left(\mathrm{F}_{2}\right.$, $102=176.60 ; \mathrm{p}<0.01)$ in Group $-1,\left(F_{2,} 96=39.33 ; \mathrm{p}<0.01\right)$ in Group-2 and $\left(\mathrm{F}_{2,90}=24.98 ; \mathrm{p}<0.01\right)$ in Group-3.

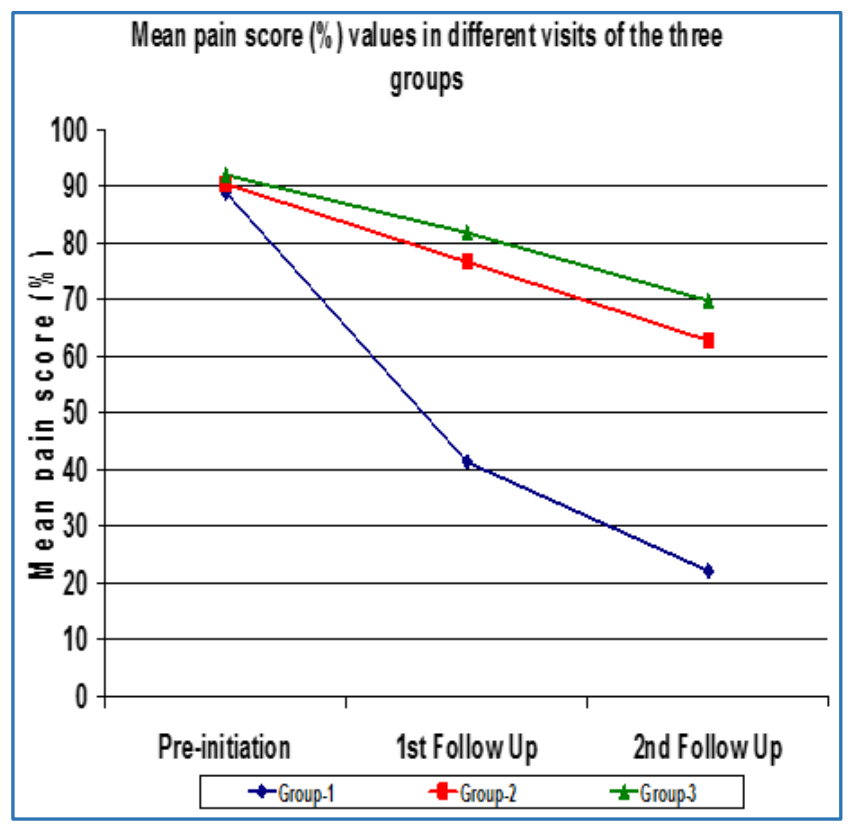

Figure 1

\begin{tabular}{|c|c|c|c|}
\hline $\begin{array}{c}\text { Groups and Other } \\
\text { Statistical } \\
\text { Parameters } \\
\end{array}$ & $\begin{array}{c}\text { Pre- } \\
\text { Initiation } \\
\text { (D1\%) }\end{array}$ & $\begin{array}{c}\text { 1st } \\
\text { Follow-up } \\
\text { (D2\%) }\end{array}$ & $\begin{array}{c}2^{\text {nd }} \\
\text { Follow-up } \\
\text { (D3\%) }\end{array}$ \\
\hline Group I ( $\mathrm{n}=35)$ & $91.61 \pm 1.41$ & $49.21 \pm 3.22$ & $26.12 \pm 3.29$ \\
\hline Group-2 (n= 33) & $92.38 \pm 1.37$ & $79.04 \pm 2.21$ & $65.28 \pm 2.39$ \\
\hline Group-3 (n= 31) & $93.58 \pm 1.49$ & $82.73 \pm 1.82$ & $72.89 \pm 2.11$ \\
\hline ANOVA F $_{2,96}$ & 0.47 & 52.97 & 88.04 \\
\hline p-values & $>0.05$ & $<0.01$ & $<0.01$ \\
\hline $\begin{array}{c}\text { At } 5 \% \text { level of } \\
\text { significance }\left(\mathrm{CD}_{5}\right)\end{array}$ & 13.32 & 23.85 & 25.23 \\
\hline $\begin{array}{c}\text { At } 1 \% \text { level of } \\
\text { significance }\left(\mathrm{CD}_{1}\right)\end{array}$ & 17.60 & 31.52 & 33.34 \\
\hline \multicolumn{4}{|c|}{$\begin{array}{c}\text { Table 2. SPADI Disability Score (D\%) (Mean } \pm \text { S.E.) } \\
\text { at Different Visits \& Statistical Analysis }\end{array}$} \\
\hline
\end{tabular}

There were no significant differences in D1\% of the three groups $\left(F_{2,96}=0.47 ; p>0.05\right)$. As per the $C D$, there were no significant differences in the mean D1\% values of the three groups ( $\mathrm{p}>0.05)$.

There were significant differences of D2\% of the three groups $\left(F_{2,} 96=52.97 ; p<0.01\right)$. As per the $C D$, the mean $D 2 \%$ was significantly lowest in Group-1 as compared to Group-2 and Group-3 ( $p<0.05)$. But there was no significant difference in mean D2\% of Group-2 and Group-3 ( $>>0.05$ ).

There were significant differences of D3\% of the three groups $\left(\mathrm{F}_{2,96}=86.35 ; \mathrm{p}<0.01\right)$. As per the $\mathrm{CD}$ the values of mean D3\% was significantly lowest in Group-1 compared to that of Group-2 and Group-3 $(\mathrm{p}<0.05)$. But there was no significant difference in mean D3\% for Group-2 and Group-3 ( $>>0.05)$.

There was significant reduction in mean values of disability scale (\%) in subsequent follow-ups $\left(\mathrm{F}_{2,102}=142.02\right.$; $\mathrm{p}<0.01)$ in Group-1, $\left(\mathrm{F}_{2,}, 96=44.01 ; \mathrm{p}<0.01\right)$ in Group-2 and $\left(F_{2,90}=32.02 ; p<0.01\right)$ in Group 3 .

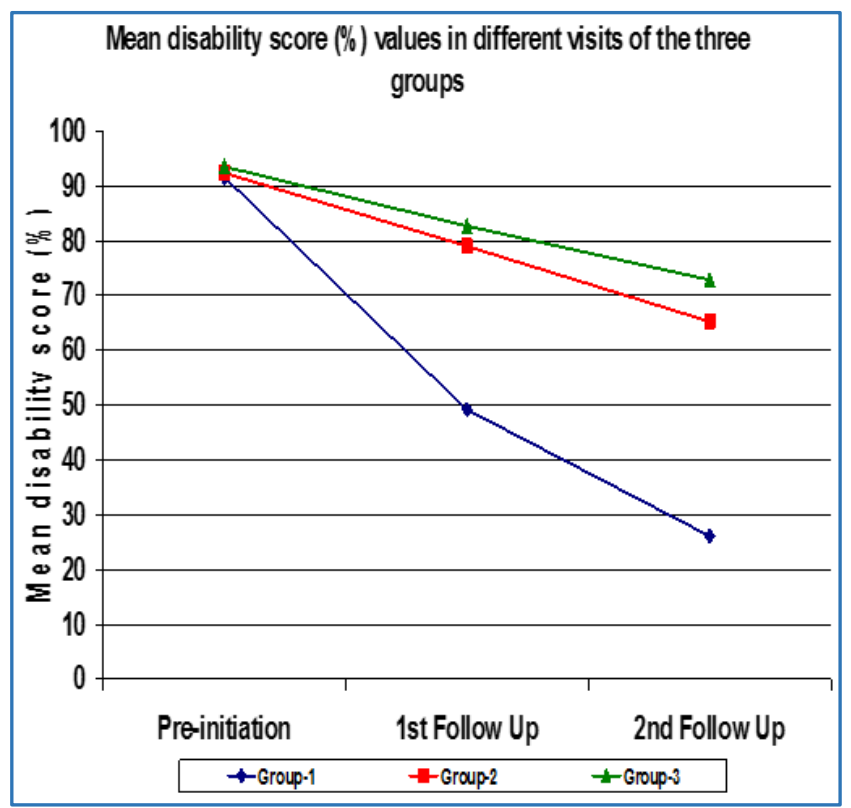

Figure 2 


\begin{tabular}{|c|c|c|c|}
\hline $\begin{array}{c}\text { Groups and } \\
\text { Other Statistical } \\
\text { Parameters }\end{array}$ & $\begin{array}{c}\text { Pre- } \\
\text { Initiation } \\
\text { (SPADI1\%) }\end{array}$ & \begin{tabular}{|c|}
$1^{\text {st }}$ \\
Follow-up \\
(SPADI2\%) \\
\end{tabular} & $\begin{array}{c}2^{\text {nd }} \\
\text { Follow-up } \\
\text { (SPADI3\%) }\end{array}$ \\
\hline Group-1 $(n=35)$ & $90.58 \pm 1.39$ & $45.89 \pm 2.88$ & $28.92 \pm 3.79$ \\
\hline Group-2 (n=33) & $91.61 \pm 1.43$ & $78.48 \pm 2.24$ & $64.70 \pm 2.29$ \\
\hline Group-3 (n=31) & $92.97 \pm 1.51$ & $82.36 \pm 1.81$ & $72.36 \pm 2.09$ \\
\hline ANOVA F $_{2,96}$ & 0.67 & 71.01 & 64.87 \\
\hline p-values & $>0.05$ & $<0.01$ & $<0.01$ \\
\hline $\begin{array}{c}\text { At } 5 \% \text { level of } \\
\text { significance }\left(\mathrm{CD}_{5}\right)\end{array}$ & 13.50 & 22.45 & 27.14 \\
\hline $\begin{array}{c}\text { At } 1 \% \text { level of } \\
\text { significance }\left(\mathrm{CD}_{1}\right)\end{array}$ & 17.84 & 29.67 & 35.87 \\
\hline \multicolumn{4}{|c|}{$\begin{array}{c}\text { Table 3. Total SPADI Score (\%) (Mean } \pm \text { S.E.) } \\
\text { at Different Visits \& Statistical Analysis }\end{array}$} \\
\hline
\end{tabular}

There were no significant differences in SPADI1\% of the three groups $\left(F_{2,96}=0.67 ; p>0.05\right)$. As per the $C D$, there were no significant differences in the mean SPADI\% values of the three groups ( $\mathrm{p}>0.05)$.

There were significant differences of SPADI2\% of the three groups $\left(F_{2,96}=71.01 ; p<0.01\right)$. As per the $C D$, the mean SPADI2\% was significantly lowest in Group-1 as compared to Group-2 and Group-3 ( $<<0.05)$. But there was no significant difference in mean SPADI2\% of Group-2 and Group-3 ( $p>0.05)$.

There were significant differences of SPADI3\% of the three groups $\left(F_{2,96}=64.87 ; p<0.01\right)$. As per the $C D$, the values of mean SPADI3\% was significantly lowest in Group-1 compared to that of Group-2 and Group-3 ( $\mathrm{p}<0.05)$. But there was no significant difference in mean SPADI3\% for Group-2 and Group-3 ( $\mathrm{p}>0.05)$.

There was significant reduction in mean SPADI (\%) in subsequent follow-ups $\left(\mathrm{F}_{2}, 102=123.21 ; \mathrm{p}<0.01\right)$ in Group- 1 , $\left(\mathrm{F}_{2,96}=43.86 ; \mathrm{p}<0.01\right)$ in Group -2 and $\left(\mathrm{F}_{2,90}=31.91 ; \mathrm{p}<0.01\right)$ in Group-3.

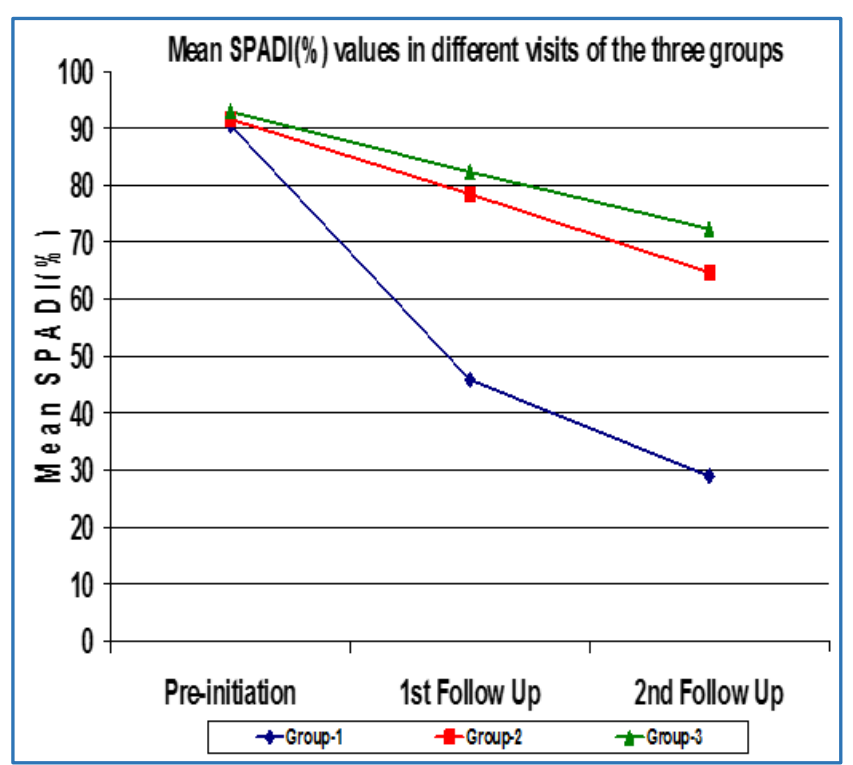

Figure 3

\begin{tabular}{|c|c|c|c|}
\hline $\begin{array}{c}\text { Groups and } \\
\text { other Statistical } \\
\text { Parameters }\end{array}$ & $\begin{array}{c}\text { Pre- } \\
\text { initiation } \\
\text { (P. Abd1) }\end{array}$ & $\begin{array}{c}\text { 1st }_{\text {Follow-up }} \\
\text { (P. Abd2) }\end{array}$ & $\begin{array}{c}\mathbf{2}^{\text {nd }} \\
\text { Follow-up } \\
\text { (P. Abd3) }\end{array}$ \\
\hline Group-1 (n = 35) & $88.71 \pm 2.95$ & $122.05 \pm 3.25$ & $143.11 \pm 3.32$ \\
\hline Group-2 (n = 33) & $92.42 \pm 2.15$ & $106.51 \pm 2.45$ & $120.48 \pm 2.52$ \\
\hline Group-3 (n = 31) & $95.80 \pm 2.28$ & $104.03 \pm 2.31$ & $114.03 \pm 2.38$ \\
\hline ANOVA F2, 96 & 1.97 & 12.88 & 29.89 \\
\hline p-values & $>0.05$ & $<0.01$ & $<0.01$ \\
\hline $\begin{array}{c}\text { At 5\% level of } \\
\text { significance (CD })\end{array}$ & 23.55 & 15.37 & 21.14 \\
\hline $\begin{array}{c}\text { At 1\% level of } \\
\text { significance (CD } 1)\end{array}$ & 31.13 & 33.94 & 34.76 \\
\hline
\end{tabular}

Table 4. Passive Abduction (P. Abd.) (in degrees) (Mean \pm S.E.) at Different Visits \& Statistical Analysis

There were no significant differences of P. Abd1 of different groups $\left(F_{2}, 96=1.97 ; p>0.05\right)$. As per the $C D$, there was no significant difference in mean $P$. Abd1 values of the three groups ( $\mathrm{p}>0.05)$.

There were significant differences of $\mathrm{P}$. Abd2 of different groups $\left(F_{2}, 96=12.88 ; p<0.01\right)$. As per the $C D$, the values of mean P. Abd2 was significantly highest in Group-1 as compared to Group-2 and Group-3 ( $\mathrm{p}<0.05)$. But there was no significant difference in mean P. Abd2 for Group-2 and Group-3 ( $>0.05)$.

There were significant differences of P. Abd3 of different groups $\left(F_{2}, 96=29.89 ; p<0.01\right)$. As per the $C D$, the mean $P$. Abd3 of Group-1 was significantly highest as compared to Group-2 and Group-3 ( $\mathrm{p}<0.05)$. But there was no significant difference in mean P. Abd3 for Group-2 and Group-3 ( $\mathrm{p}>0.05)$.

There was significant reduction in mean P. Abd. (in degrees $)$ in subsequent follow-ups $\left(F_{2,102}=74.11 ; p<0.01\right)$ in Group-1, $\left(\mathrm{F}_{2,96}=34.66 ; \mathrm{p}<0.01\right)$ in Group -2 and $\left(\mathrm{F}_{2,90}=15.39\right.$; $\mathrm{p}<0.01$ ) in Group-3.

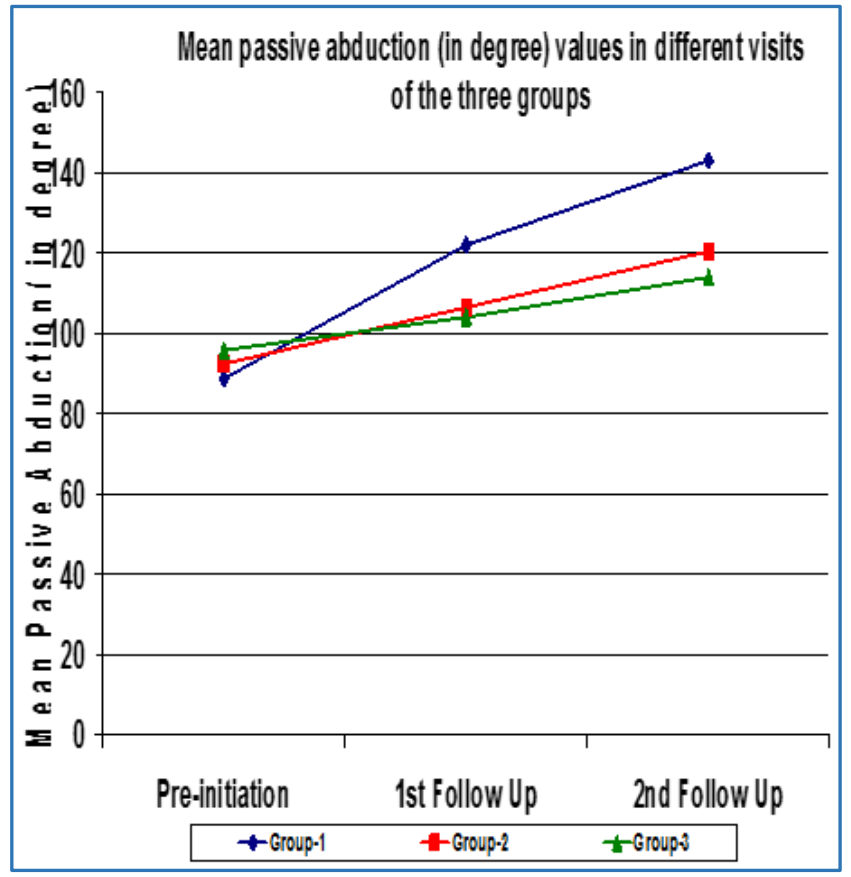

Figure 4 


\begin{tabular}{|c|c|c|c|}
\hline $\begin{array}{c}\text { Groups and } \\
\text { other statistical } \\
\text { parameters }\end{array}$ & $\begin{array}{c}\text { Pre- } \\
\text { initiation } \\
\text { (P. Ext. } \\
\text { Rot1) }\end{array}$ & $\begin{array}{c}\mathbf{1}^{\text {st }} \\
\text { Follow-up } \\
\text { (P. Ext. Rot2) }\end{array}$ & $\begin{array}{c}\mathbf{2}^{\text {nd }} \\
\text { Follow-up } \\
\text { (P. Ext. Rot3) }\end{array}$ \\
\hline Group- I (n = 35) & $26.51 \pm 1.31$ & $40.51 \pm 2.14$ & $52.45 \pm 2.41$ \\
\hline Group- II (n = 33) & $24.96 \pm 1.07$ & $30.24 \pm 1.18$ & $38.45 \pm 1.38$ \\
\hline Group- III (n = 31) & $24.58 \pm 0.97$ & $28.77 \pm 1.04$ & $34.77 \pm 1.20$ \\
\hline ANOVA F $F_{2,96}$ & 0.81 & 16.58 & 27.30 \\
\hline p-values & $>0.05$ & $<0.01$ & $<0.01$ \\
\hline $\begin{array}{c}\text { At 5\% level of } \\
\text { significance (CD })\end{array}$ & 10.67 & 9.33 & 13.82 \\
\hline $\begin{array}{c}\text { At 1\% level of } \\
\text { significance (CD })\end{array}$ & 14.10 & 19.60 & 22.23 \\
\hline \multicolumn{4}{|c|}{ Table 5. Passive External Rotation (in degrees) } \\
(Mean \pm S.E.) at Different Visits \& Statistical Analysis \\
\hline
\end{tabular}

There were no significant differences of P. Ext. Rot1 of different groups $\left(F_{2}, 96=0.81 ; p>0.05\right)$. As per the $C D$, there was no significant difference in mean P. Ext. Rot1 values of the three groups ( $p>0.05)$.

There were significant differences of P. Ext. Rot2 of different groups $\left(F_{2}, 96=16.58 ; p<0.01\right)$. As per the $C D$, the values of mean P. Ext. Rot2 was significantly highest in Group- 1 as compared to Group-2 and Group-3 ( $\mathrm{p}<0.05)$. But there was no significant difference in mean P. Ext. Rot2 for Group-2 and Group-3 ( $\mathrm{p}>0.05)$.

There were significant differences of P. Ext. Rot3 of different groups $\left(F_{2,96}=27.30 ; p<0.01\right)$. As per the $C D$, the mean P. Ext. Rot3 of Group-1 was significantly highest as compared to Group-2 and Group-3 ( $\mathrm{p}<0.05)$. But there was no significant difference in mean P. Ext. Rot3 for Group-2 and Group-3 ( $\mathrm{p}>0.05)$.

There was significant reduction in mean P. Ext. Rot. (in degrees) in subsequent follow-ups: $F_{2,102}=41.63, p<0.01$ in Group-1; $F_{2,96}=31.01, p<0.01$ in Group-2; and $F_{2}, 90=22.47$, $\mathrm{p}<0.01$ in Group 3.

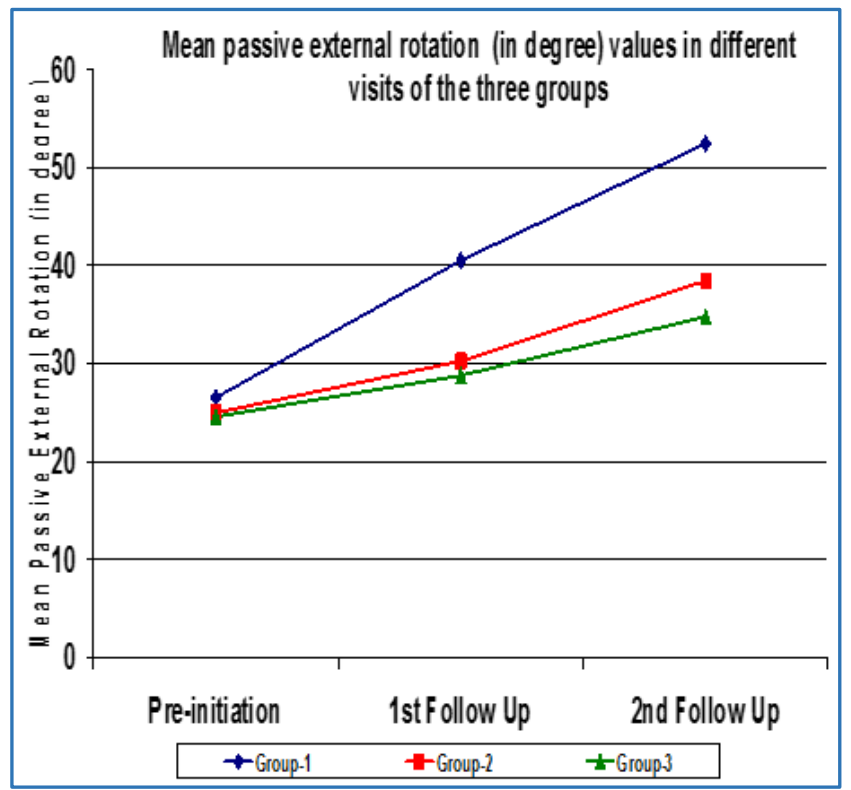

Figure 5

\section{DISCUSSION}

Although frozen shoulder is a self-limiting condition, it imposes such morbidity and lengthy recovery time that patients and clinicians alike seek treatment interventions. No standard treatment regimen, however, is accepted universally. Educating patients will help to reduce frustration and encourage compliance. Time should be taken to explain the condition to the patient. Specific information on the natural history of the disease and an explanation that it will resolve spontaneously should be provided. It should be remembered, though, that the full range of motion might never be restored as shown in some of the aforementioned studies. A decision regarding the best treatment option depends on the stage of the disease and clinical symptoms. There is, however, still no consensus on a standard management protocol. This is understandable if you consider the opinion of Lubiecki et al(12) who came to the conclusion that there is no conclusive evidence on the superiority of any of the known published interventions. The study was based on the fact that there is no 'robust data' available that compared to any specific treatment with the natural history of the disease.

Although many interventions have been advocated for the treatment of adhesive capsulitis, the efficacy of treatments for adhesive capsulitis has rarely been evaluated in randomized comparative studies. Based on the limited quantity of high grade evidence, it has been concluded that the treatment options have no superiority over each other in the longterm. Nevertheless, some differences may exist in the early phase of treatment.

One important factor for rehabilitation of patients with adhesive capsulitis is that of the decrease in shoulder pain. In addition to NSAIDs, heat modalities and steroid injections may reduce the pain and thus improve the exercise tolerance. $(2,3,4)$ In our study, the shoulder pain significantly decreased after treatment consisting of steroid injection, heat modalities and NSAIDs as compared to its initial level.

From statistical analysis of this study, we concluded that intra-articular steroid injection with conventional exercises, produce faster resolution of adhesive capsulitis as compared to UST with conventional exercise therapy or conventional exercise therapy only. Lee $\mathrm{M}$ et al,(13) Carette et al(14) and Bulgen D et al(15) also supported to intra-articular injection with exercises but Rizk TE(16) et al disagreed to benefit of intra-articular steroid injection.

Van der Windt et al also compared glenohumeral injection of corticosteroid to 6 weeks of physical therapy for patients with painful stiff shoulders. They found significant improvements in pain, disability, and motion in the injection group at 3 and 7 weeks.(17) Response to intra-articular steroid was not related to stage of disease. However, at 26 and 52 weeks, there was minimal or nil difference between the two groups.

UST with conventional exercises does not produce statistically significant benefit in comparison to only conventional exercise therapy group in rehabilitation of Adhesive capsulitis of shoulder. UST is the most commonly prescribed deep heat modality in frozen shoulder but it does not show any significant improvement.

We hypothesised in this study that early treatment with intra-articular corticosteroid provides a chemical ablation of the synovitis, thus limiting the subsequent development of fibrosis and shortening the natural history of the disease. The self-limiting nature of adhesive capsulitis also supports the role of the synovium in initiation and regulation of the fibrotic process in the capsule. With resolution of the 
synovitis and termination of capsular scar formation, capsular remodelling and recovery of ROM occurs. This hypothesis is supported by the orthopaedic and rheumatologic literature. ${ }^{(18,19)}$

Adhesive capsulitis of shoulder usually resolves spontaneously so the aim of therapy is to speed up the natural progression of the condition. Active, passive and assisted range-of-motion exercises are essential in the early stages of rehabilitation. Any pain-relieving modalities were also appropriate when discomfort prevents attempted rangeof-motion exercises. When pain is still a major symptom, care must be taken to work the arm only in available range, while pain relieving modalities remain the treatment of choice. Our study showed that intra-articular injections act as a better pain relieving modalities as compared to Ultrasound therapy (UST). In this study, UST did not produce any significant improvement in rehabilitation of group-2 patients as compared to control group (group-3).

\section{CONCLUSION}

Adhesive capsulitis of shoulder usually resolves spontaneously so the aim of therapy is to speed up the natural progression of the condition. Active, passive and assisted range of motion exercises are essential in the early stages of rehabilitation. Any pain-relieving modalities are also appropriate when discomfort prevents attempted range-ofmotion exercises. When pain is still a major symptom, care must be taken to work the arm only in available range, while pain relieving modalities remain the treatment of choice. Our study showed that intra-articular injections act as a better pain relieving modality as compared to Ultrasound therapy (UST). In this study, UST did not produce any significant improvement in rehabilitation of group-2 patients as compared to control group (Group 3). Ultrasound therapy only shows placebo effect in Adhesive capsulitis of shoulder. This study advocates that intra-articular steroid injection should be the treatment of choice with exercise.

\section{REFERENCES}

[1] Codman EA. The shoulder: rupture of the supraspinatus tendon \& other lesions or about the subacromial bursa. Boston, MA: Thomas Todd Company 1934:216-24.

[2] Solomon L, Warwick D, Nayagam S. Apley's system of orthopedics and fractures. 9 $9^{\text {th }}$ edn. Hodder Arnold 2010:351-3.

[3] Braddom RL. Physical Medicine \& Rehabilitation. $3^{\text {rd }}$ edn. Elsevier 2008:834-5.

[4] Ebnezar J. Textbook of Orthopaedics. $4^{\text {th }}$ edn. Jaypee Publishers 2010:378-80.
[5] Grey RG. The natural history of "idiopathic" frozen shoulder. J Bone Joint Surg Am 1978;60(4):564.

[6] Reeves B. The natural history of the frozen shoulder syndrome. Scand J Rheumatol 1975;4(4):193-6.

[7] Depalma AF. Loss of scapulohumeral motion (frozen shoulder). Ann Surg 1952;135(2):193-204.

[8] Simmonds FA. Shoulder pain with particular reference to the frozen shoulder. J Bone Joint Surg 1949;31B(3):426-32.

[9] Hand C, Clipsham K, Rees JL, et al. Long term outcome of frozen shoulder. J Shoulder Elbow Surg 2008;17(2):231-6.

[10] Dudkiewicz I, Oran A, Salai M, et al. Idiopathic adhesive capsulitis: long term results of conservative treatment. Isr Med Assoc J 2004;6(9):524-6.

[11] Shaffer B, Tibone JE, Kerlan RK. Frozen shoulder. A long term follow up. J Bone Joint Surg Am 1992;74(5):738-46.

[12] Lubiecki M, Carr A. Frozen shoulder: past, present and future. J Orthop Surg 2007;15(1):1-3.

[13] Lee M, Haq AM, Wright V, et al. Periarthritis of the shoulder: a controlled trial of physiotherapy. Physiotherapy 1973;59(10):312-5.

[14] Carette S, Moffet H, Tardif J, et al. Intraarticular corticosteroids, supervised physiotherapy or a combination of the two in the treatment of adhesive capsulitis of the shoulder: a placebo-controlled trial. Arthritis Rheum 2003;48(3):829-38.

[15] Bulgen DY, Binder AL, Hazleman BL, et al. Frozen shoulder: prospective clinical study with an evaluation of three treatment regimes. Ann Rheum Dis 1984;43(3):353-60.

[16] Rizk TE, Pinals RS, Talaver AS. Corticosteroid injections in adhesive capsulitis: investigation of their value and site. Arch Phys Med Rehabil 1991;72(1):202.

[17] Van der Windt DA, Koes BW, Deville W, et al. Effectiveness of corticosteroid injections versus physiotherapy for treatment of painful stiff shoulder in primary care: randomised trial. BMJ 1998;317(7168):1292-6.

[18] Rodeo SA, Hannafin JA, Tom J, et al. Immunolocalization of cytokines and their receptors in adhesive capsulitis of the shoulder. J Orthop Res 1997;15(3):427-36.

[19] Bunker TD, Anthony PP. The pathology of frozen shoulder. A Dupuytren-like disease. J Bone Joint Surg Br 1995;77(5):677-83. 